\title{
ESTUDO DOS PROCESSOS EROSIVOS INSTALADOS NA PRAIA DE PIPA- RN
}

\author{
SCUDELARI, A.C.; BRAGA, K.G.; COSTA, F.A.A. \& SANTOS Jr., O.F. \\ UFRN - Universidade Federal do Rio Grande do Norte
}

\begin{abstract}
Scudelari, A.C.; Braga, K.G.; Costa, F. A. A. \& Santos Jr., O.F. 2005. Erosive processes study that affecting Pipa beach - RN. Braz. J. Aquat. Sci. Technol. 9(1):31-37. ISSN 1808-7035. The coastal zone of Rio Grande do Norte has great natural beauties, excelling Pipa Beach in the southern region of the state. It is located in the Municipal district of Tibau do Sul and has exuberant cliffs. However, this beach is being affected by erosive processes in conflict with the local tourist activity, which is in expansion. Such fact ally to the economical pressure of the real estate occupation generates significant environmental impacts, once the coastal atmosphere is very delicate and fragile, and any change that reaches it, produces alterations in all the involved natural factors. So, the present work has an objective to characterize the erosive processes in full detail that are affecting central part of Pipa Beach, located between Ponta do Madeiro and Ponta da Pedra do Moleque, in order to subsidize the development of an occupation zoning with base with these erosive processes, in way to minimize the installed conflicts. Field works were accomplished, walking along the whole central part (with approximately $5 \mathrm{~km}$ ) and photographing active erosive processes, being these presented by sub-parts.
\end{abstract}

Keywords: Erosive processes; Pipa beach; Cliffs.

\section{INTRODUÇÃO}

A zona costeira do Rio Grande do Norte possui grandes belezas naturais, destacando-se no litoral oriental sul a praia de Pipa, situada no Município de Tibau do Sul, com suas exuberantes falésias. Atualmente, esta praia está sendo afetada por processos erosivos em conflito com a atividade turística local em expansão. Tal fato, aliado à pressão econômica da ocupação imobiliária provoca sérios impactos ambientais, uma vez que o ambiente costeiro é delicado e frágil, e qualquer mudança que o atinja provoca alterações em todos os fatores naturais envolvidos.

Um dos problemas relacionados à expansão do turismo local é a ocupação irresponsável da borda das falésias, que aliada à erosão costeira (avanço da linha de costa na direção do continente) vem ocasionando diversos problemas, tanto aos proprietários da terra, quanto ao poder público e à natureza.

O litoral potiguar é caracterizado, de maneira geral, por praias arenosas interrompidas por falésias e arrecifes de arenitos, paralelos e próximos à praia. Especificamente na zona costeira da praia de Pipa estão ocorrendo mudanças nas feições da costa por causa da ação das ondas e das intensas precipitações pluviométricas. Esta zona fica entre as pontas do madeiro e da pedra do moleque (Figura 1), possui aproximadamente $5 \mathrm{~km}$ de extensão e sua formação é predominantemente de falésias.

Em alguns trechos, essas falésias vêm sofrendo sucessivos recuos, devido à ação do mar e da água das chuvas. A erosão costeira nessa área é motivo de várias pesquisas e trabalhos científicos, cuja importância reside no fato da movimentação turística na região ser muito intensa. O ecoturismo praticado em Tibau do Sul é um dos que mais se desenvolvem no Brasil, segundo dados da Secretaria de Estado do Turismo do RN (Rio Grande do Norte, 2003).

Dentro deste contexto, as ações antrópicas aliadas aos processos erosivos naturais são fatores preponderantes no equilíbrio ambiental da região. Sendo assim, é de fundamental importância identificar tais processos naturais vigentes (no caso do presente trabalho, a erosão costeira), a fim de subsidiar o entendimento da capacidade de suporte do meio às atividades humanas desenvolvidas na região.

\section{Processos erosivos e movimentos de massas em en- costas}

As feições morfológicas que compõem a paisagem do planeta foram e são continuamente esculpidas por agentes modeladores externos desde milhares de anos atrás. Entre estes agentes, os mais importantes são: as chuvas, as marés e os vários tipos de intemperismo. A ação deles é geralmente no sentido de tornar o relevo plano. Contrapondo-se a essa ação, tem-se a resistência dos materiais que compõem as superfícies naturais. Quando os agentes modeladores externos atuam com intensidade superior à resistência dos materiais que formam uma encosta, podem ocorrer processos erosivos ou movimentos gravitacionais de massa. 


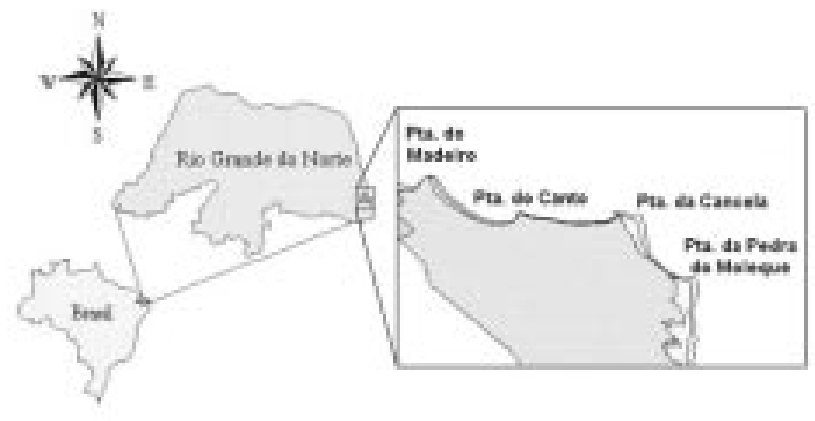

Figura 1 - Localização da área de estudo.

São vários os tipos de erosão em encostas, dentre os quais destacam-se: pluvial, costeira, eólica e glacial. Nas falésias da área de estudo, atuam mais intensamente a erosão pluvial e a erosão costeira.

A erosão pluvial começa no instante em que as primeiras gotas de chuva batem no solo. Tal momento é denominado de splash e pode resultar na ruptura dos agregados, selando o topo do solo e dando condições para formações de poças. A partir daí, a água começa a escoar na superfície, primeiramente em lençol, depois em fluxos lineares, evoluindo para microravinas, podendo formar cabeceiras, com algumas delas sofrendo bifurcação e formando novas ravinas. O aprofundamento das ravinas pode levar a formação de voçorocas. Estas se caracterizam por grande profundidade e formação de paredes laterais íngremes (Guerra et al., 1999).

A erosão costeira caracteriza-se como a perda ou o deslocamento de sedimentos ao longo da costa, devido à ação de ventos, ondas, correntes, marés ou tempestades. A linha de costa é um ambiente de forte dinâmica, onde ocorrem processos erosivos que promovem mudanças profundas na área, tanto a longo prazo quanto a curto. Neste ambiente, ocorrem deposições e retiradas de sedimentos indefinidamente. Quando ocorre mais retirada do que deposição caracterizase a erosão costeira, com o recuo da linha de costa em direção ao continente. Este é um problema muito comum nas regiões litorâneas, afetando principalmente os proprietários de estruturas instaladas na linha do litoral.

A ação de tais processos erosivos pode causar processos de ruptura ou de desestabilização das encostas, resultando em movimentos coletivos de solo, rocha ou mistura de solo e rocha, chamados de movimentos de massas. De maneira geral, os movimentos podem ser classificados como: quedas (o material se destaca da encosta e se movimenta em queda livre), tombamentos (o material instável cai, girando em torno de um ponto de sua base), escorregamentos ou deslizamentos (a massa instável se desloca como um bloco ao longo de uma superfície de escorregamento), escoamentos (o material em movimento sofre intensa fragmentação, passando a se comportar como um fluido viscoso em condições de alta umidade do solo) e movimentos complexos (combinação de um ou mais dos principais tipos de movimentos descritos).

\section{A dinâmica superficial em falésias}

As falésias são encostas íngremes de sedimentos pré-quaternários do grupo barreiras, verificadas ao longo do litoral nordestino. Podem estar em contato direto com as águas oceânicas, sofrendo erosão contínua pela ação marinha (falésias vivas) ou no interior do continente (falésias mortas ou recuadas).

Muitos estudos sobre falésias referem-se à obtenção da taxa de recuo a partir de comparações entre fotografias, cartas e mapas de diferentes datas. Tal recuo ocorre na forma de pulsos, desenvolvendo-se por meio de eventos esporádicos de movimentos de massas. Sua velocidade é controlada pela litologia, estratigrafia, características mecânicas dos solos e das rochas que formam as escarpas e características externas. A velocidade do recuo é uma característica inerente à área, variando de uma região para outra (Silva, 2003).

Um dos principais fatores responsáveis pelo recuo das falésias é a ação do embate de ondas no pé dos taludes costeiros, escavando a base da encosta e criando condições para o desencadeamento de movimentos de massas. Este material que se deposita na base é removido pela ação das ondas, entrando no balanço sedimentar Além disso, a erosão pluvial atuante em seu topo, com a formação de ravinas e voçorocas devido ao carreamento de partículas de sua superfície em direção à costa, influi significativamente na estabilidade de tais formações.

A evolução da estabilidade das falésias em direção à ruptura depende das características estruturais, mecânicas e hidráulicas da massa de solo ou rocha e de sua resposta às solicitações externas. O conhecimento de tais processos é necessário para que se possa determinar a vulnerabilidade das falésias e ao mesmo tempo subsidiar uma política de gerenciamento das zonas costeiras (Silva, 2003).

\section{Descriçãp da área estudada}

No litoral oriental sul potiguar, localiza-se o município de Tibau de Sul, e nele está inserida a área objeto de estudo do presente trabalho. Foi feita neste município uma subdivisão da zona costeira em: trecho norte, trecho central e trecho sul (Amaral, 2001). O trecho norte está compreendido entre a barra de Tibau do Sul e a Ponta do Madeiro, possuindo orientação apro- 
ximadamente norte-sul. O trecho central inicia-se na Ponta do Madeiro e vai até a Pedra do Moleque, com orientação leste-oeste. $O$ trecho sul começa na Pedra do Moleque e culmina na desembocadura do rio Catú ou Cibaúma, com orientação Norte-Sul. Em toda área, ocorrem falésias com altura variando de 20 a 40 metros. Este trabalho está limitado à análise dos processos erosivos pertinentes ao trecho central, tendo ele aproximadamente $5 \mathrm{~km}$. A figura 2 identifica todos os pontos de referência utilizados por Amaral (2001) para elaboração do zoneamento e mapeamento do município.

\section{Processos erosivos no trecho estudado}

Segundo Silva (2003), o trecho central caracteriza-se por uma seqüência de praias intercaladas por formações rochosas, compostas por arenitos ferruginosos. Embora este trecho sofra influência tanto de processos de origem continental quanto marinha, observa-se que a agressão promovida pela erosão costeira supera, em termos degradacionais, os impactos promovidos pela erosão pluvial e pelos movimentos gravitacionais de massa. Isto se deve basicamente à remoção de corpos de detritos na base e conseqüente formação de incisões.
No presente trabalho, foi realizada uma pesquisa de campo com base na identificação dos processos erosivos ao longo da costa escarpada, percorrendo-se todo o trecho e registrando, tanto na faixa de praia, quanto no topo das falésias, as erosões atuantes e seus desencadeadores. Para facilitar a apresentação dos dados, o trecho central foi divido em três sub-trechos (Figura 3 e 4). Essa divisão foi realizada levandose em consideração o nível de ocupação do solo, já que as construções e edificações humanas na costa em conflito com os processos erosivos instalados geram relevantes problemas ambientais.

\section{Sub-trecho 1}

O sub-trecho 1 é limitado fisicamente a Oeste pela Ponta do Madeiro e a Leste pela Ponta do Canto. Possui falésias recuadas com altura de aproximadamente $35 \mathrm{~m}$ e perfil de inclinação forte. Este sub-trecho é localizado em uma área de preservação ambiental (santuário ecológico), possuindo vegetação densa no topo das falésias em quase toda sua extensão. Na sua parte média, observa-se vegetação em toda a encosta, cobrindo topo, face e base.

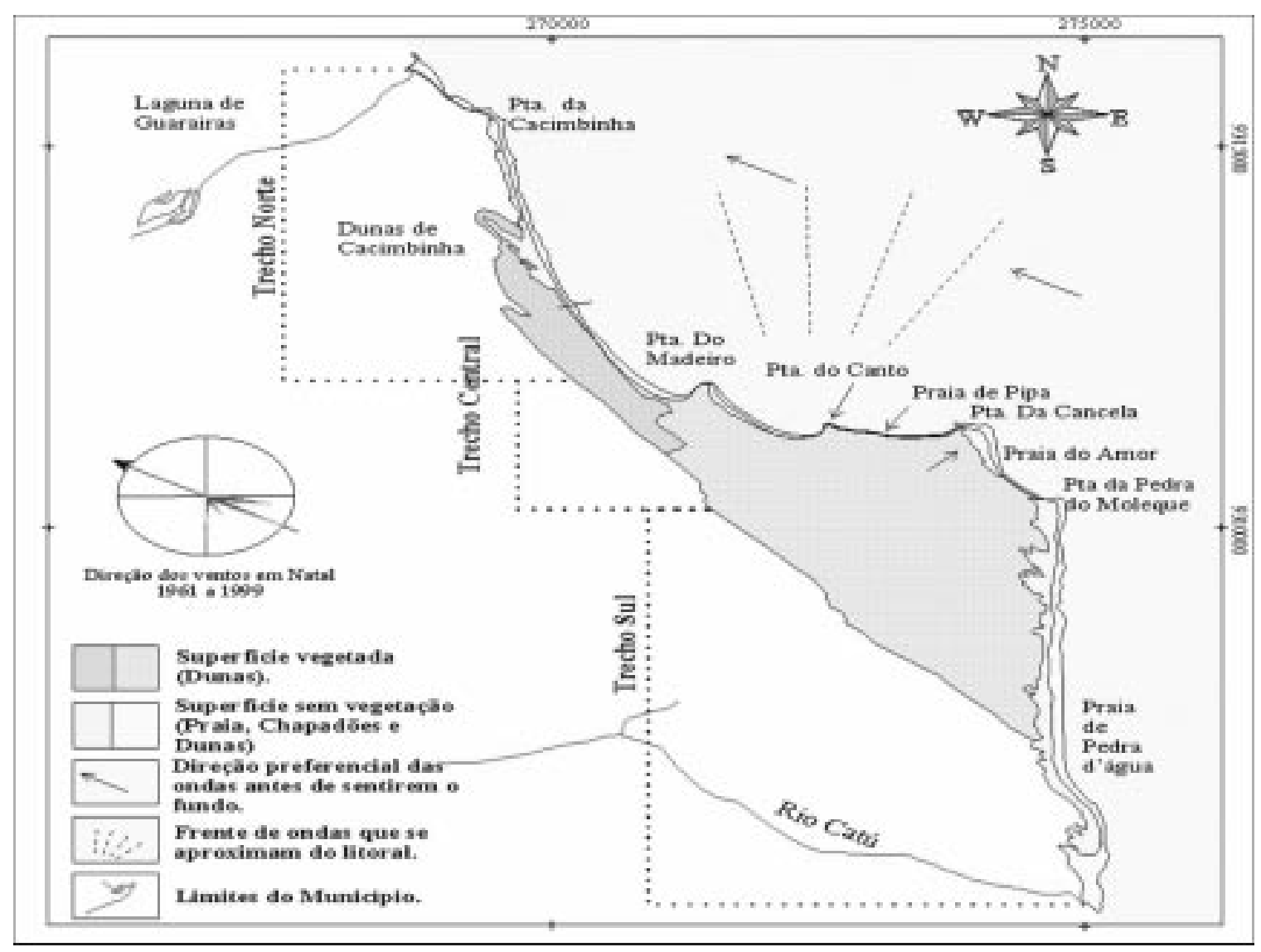

Figura 2 - Zoneamento geomorfológico da área mapeada (Amaral,2001). 


\section{ESQUEMA DO TRECHO CENTRAL}

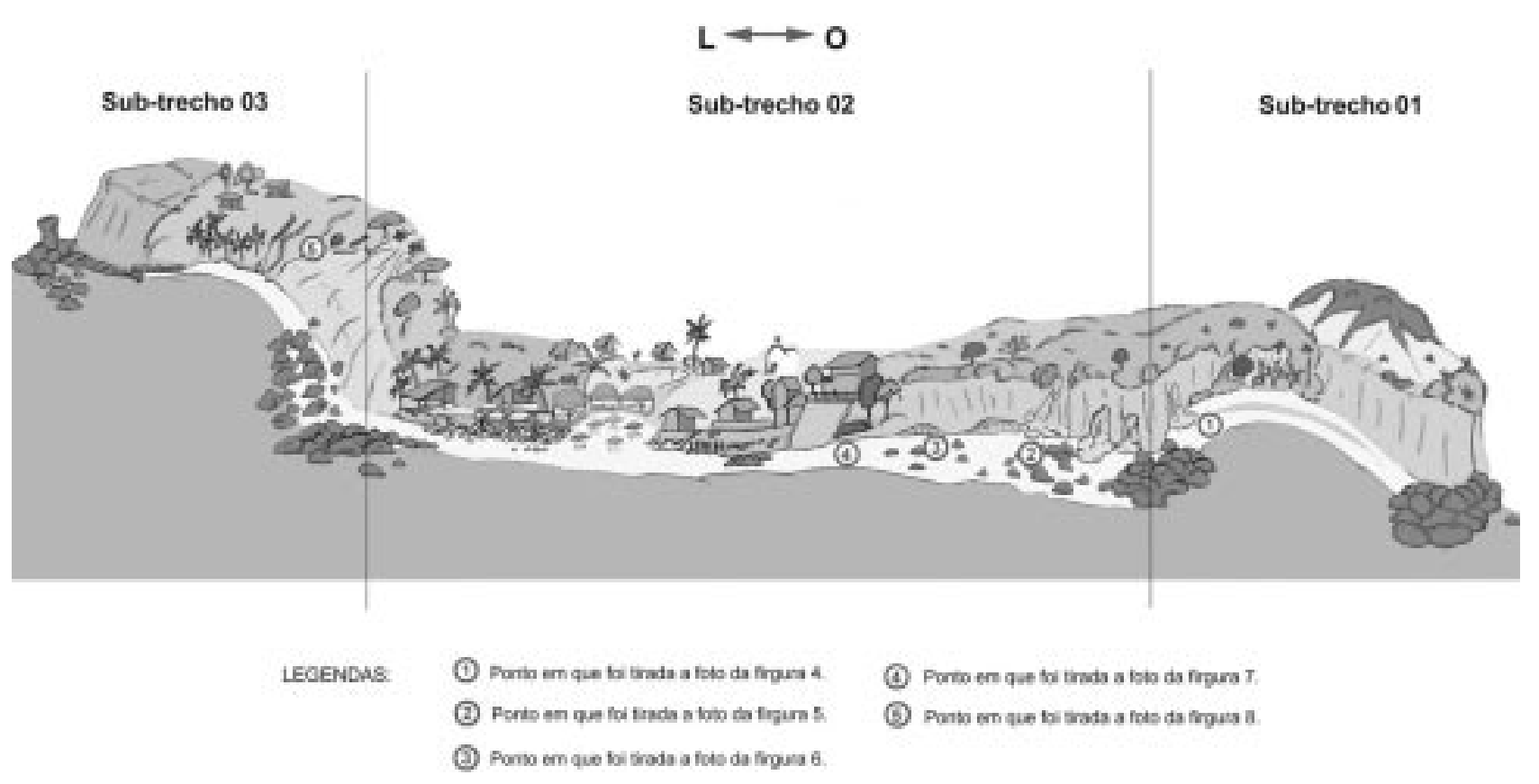

Figura 3 - Panorama da área de estudo com a localização das fotos.

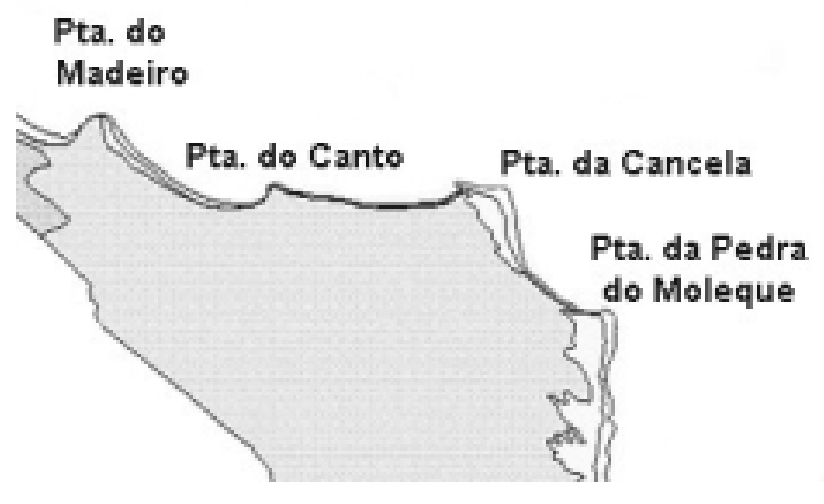

Figura 4 - Divisão dos sub-trechos.

Este sub-trecho é completamente desabitado, não apresentando, portanto, conflitos entre obras antrópicas e processos erosivos naturais. Entretanto, em alguns pontos do mesmo, verifica-se a ocorrência de movimentos de massas, principalmente quedas e tombamentos (Figura 5), pelo fato da encosta ser íngreme, não ser vegetada na face e ter padrão de fraturamento que proporciona a compartimentação do maciço na forma de blocos. Tal fenômeno contribui para a formação de depósitos de tálus no sopé das falésias, guarnecendo-as contra a ação das ondas e fornecendo sedimentos à faixa de praia.

A proteção conferida pela vegetação às falésias desse sub-trecho, bem como a ausência de planícies de escoamento, faz com que as mesmas não sofram intensamente com a erosão pluvial, não se verificando a formação de ravinas ou voçorocas em sua extensão. Também não se observa a erosão costeira de maneira relevante, devido à presença de bermas, arenitos ferruginosos e uma faixa de praia na maré cheia, que dissipam a energia das ondas incidentes, protegendo o pé das encostas. Este sub-trecho caracterizase como sendo o menos afetado pelos processos erosivos, devido à inexistência de ocupação de seu solo pelo homem, por situar-se em uma área de preservação ambiental.

\section{Sub-trecho 2}

Compreendido a Oeste pela Ponta do Canto e a Leste pela Ponta da Cancela, o sub-trecho 2 é o mais habitado, apresentando forte atividade turística e sofrendo pressões do mercado imobiliário.

Em seu início (Oeste), ainda pouco habitado, as falésias são altas (aproximadamente $40 \mathrm{~m}$ ) e vegetadas apenas em seu topo, estando sujeitas a movimentos de massa, como deslizamentos, quedas e tombamentos (Figura 6), ocorridos pelos mesmos motivos citados no sub-trecho 1 e deflagrados pela água 


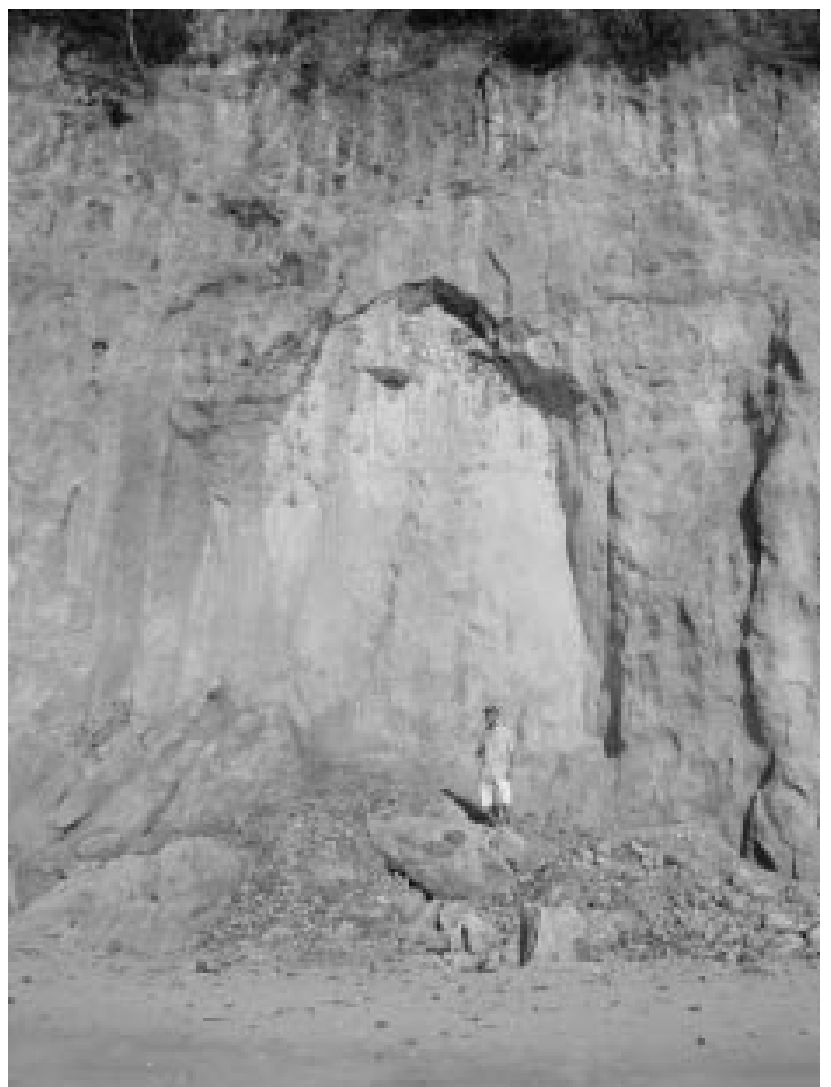

Figura 5 - Movimento de massa no final do sub-trecho 1.

de intensas chuvas tropicais que preenchem as descontinuidades do maciço e atuam no sentido de expulsar blocos do talude.

Também nessa área, as ondas escovam o pé das falésias (falésias vivas), solapando a base e formando incisões, na forma de pequenas "cavernas" (Figura 7). Essas incisões provocam instabilidade basal e conseqüente formação de depósitos de tálus. Na sua parte média e final (Leste), o sub-trecho 2 possui uma alta concentração de edificações, com pousadas, casas de veraneio, bares e restaurantes, que se estendem desde a beira-mar até o topo da encosta (de inclinação suave). A proximidade de tais obras em relação ao mar gera sérios problemas ambientais, já que o avanço da linha de costa em direção ao continente, devido à erosão costeira, choca-se com obras de proteção às construções litorâneas. Essas obras, em geral, constituem-se de enrocamentos de pedra (marroada) e muros de concreto (Figura 8), que são construídos pelos proprietários com o intuito de impedir a invasão das águas marinhas nos terrenos de seus estabelecimentos. Tais proteções antrópicas barram o ciclo natural de avanço e recuo da linha costeira e podem cortar o suprimento de sedimentos em uma dada área, agravando o fenômeno da erosão.

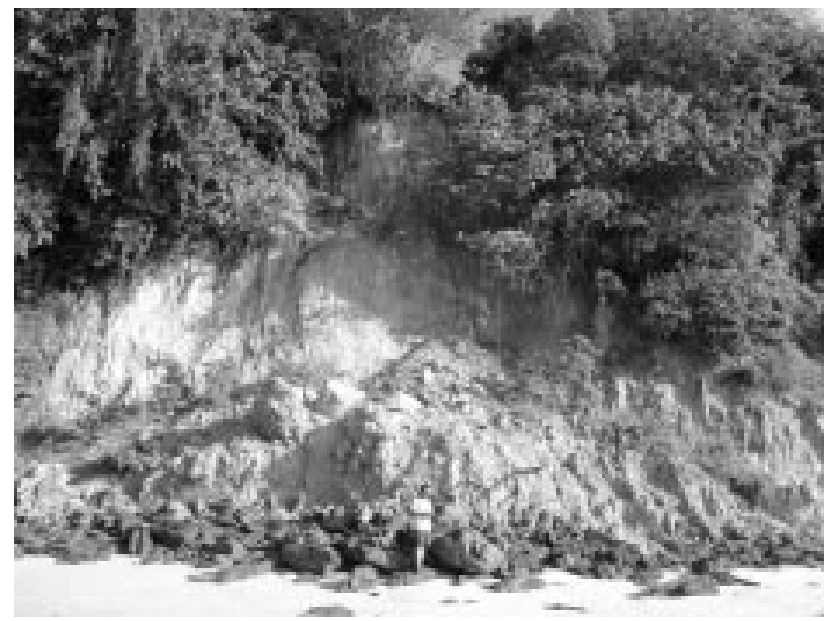

Figura 6 - Deslizamento no início do sub-trecho 2.

Pode-se observar claramente como conseqüência desse conflito instalado na Praia de Pipa, a existência de uma endentação da faixa de praia ao final de um muro de enrocamento de pedra na parte central do sub-trecho 2, onde se localizam barracas e quiosques (Ver esquema 3). Nesse local, a linha de costa avançou somente onde não havia obras de proteção, estando na iminência de desencadear processos erosivos na parte lateral e posterior de tais obras. Este é um fenômeno típico de erosão costeira.

Outro grave problema desse sub-trecho é a destruição da vegetação nativa e a alteração da topografia da encosta para a construção das casas, lojas, bares e pousadas. Isto ocasiona a impermeabilização da superfície e aumenta em muito o escoamento de águas pluviais, acentuando a erosão nas falésias adjacentes.

\section{Sub-trecho 3}

O sub-trecho 3 está localizado entre a ponta da Cancela (Oeste) e a Ponta da Pedra do Moleque, estando apenas parcialmente habitado, com alguns bares, na base das falésias, e pousadas, situadas no topo das mesmas. Nesse sub-trecho, as falésias são altas (aproximadamente $40 \mathrm{~m}$ ), com inclinações variando de suave (início - oeste) a média (final - leste) e vegetação densa (topo, face e base) apenas em sua parte central.

A erosão pluvial verifica-se fortemente no início do sub-trecho 3 (oeste), formando uma planície de escoamento, com grande quantidade de ravinas e voçorocas (Figura 9). Este processo não é intenso em sua parte média, devido à existência de proteção conferida pela vegetação, e nem na sua parte final, pois seu material é de maior resistência, não sendo significativamente erodido, por mais que se formem superfícies de escoamento. 


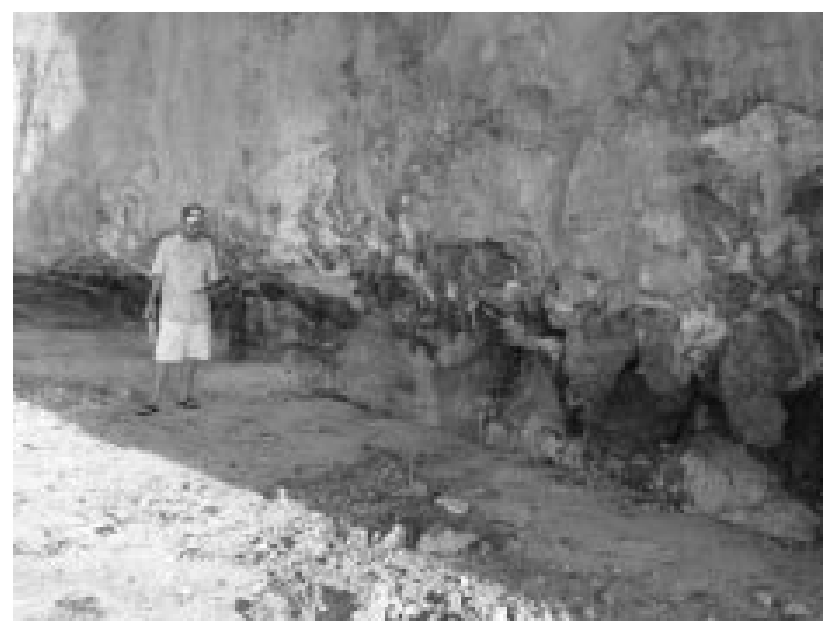

Figura 7 - Incisões na base da falésia formadas pela ação das ondas.

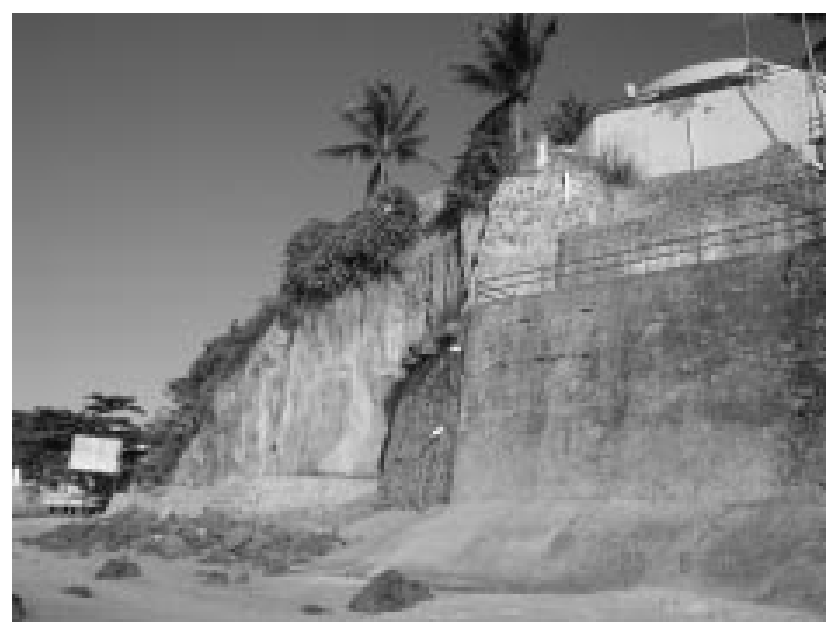

Figura 8 - Obras de proteção costeira.

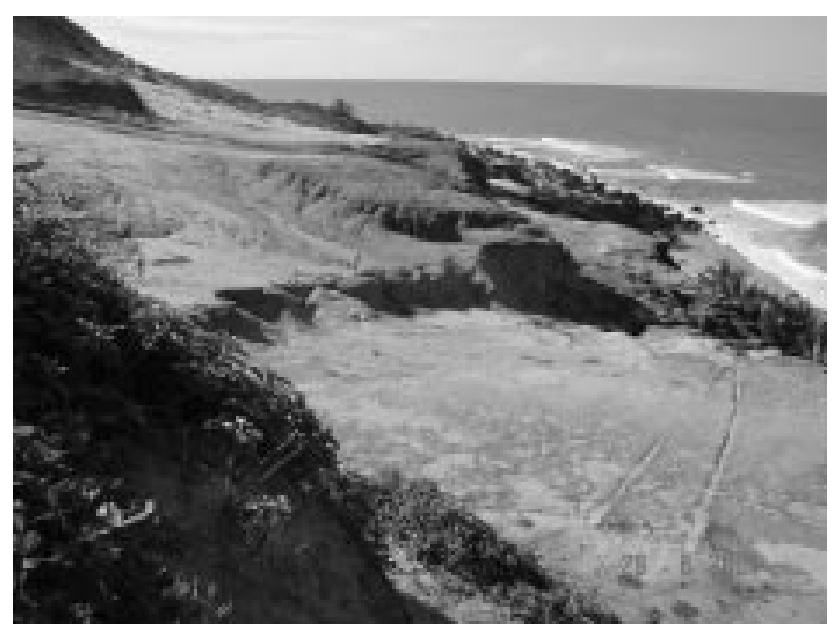

Figura 9 - Planície de escoamento, com ravinas e voçorocas.
A existência de falésias mais recuadas e arenitos ferruginosos onde as ondas possuem maior energia fazem com que a erosão costeira não seja marcante nesse sub-trecho. Nele, inexistem obras de proteção costeira. No final (leste) do sub-trecho 3 inicia-se um chapadão.

\section{CONCLUSÃO}

Verifica-se que os processos erosivos predominantes na praia de Pipa - RN são a erosão costeira e pluvial, atuantes na base e topo das falésias, respectivamente. A presença de construções, como casas de veraneio, bares, restaurantes, pousadas, entre outros, ao longo da costa, principalmente para servir ao turismo, agravam os conflitos gerados pela erosão, criando situações de risco ao meio ambiente e às próprias edificações. Tais riscos envolvem: as alterações da linha de costa, que avança em direção ao continente em algumas áreas devido às mudanças no balaço de sedimentos; o recuo das falésias pela ação erosiva das ondas e da água de precipitação, ameaçando as obras situadas em seu topo; a formação de planícies de escoamento com grandes ravinas e voçorocas, que podem solapar as bases edificações próximas; e a ocorrência de grandes movimentos de massa, como quedas, tombamentos e deslizamentos.

A fim de preservar o equilíbrio costeiro e ambiental da área estudada, são de fundamental importância a criação e realização de medidas, estruturais e não-estruturais, que envolvam, principalmente, o desenvolvimento de um zoneamento de ocupação, com base na evolução da linha de costa natural, de forma a minimizar os conflitos instalados.

\section{REFERÊNCIAS}

Rio Grande do Norte. 2003.Os Impactos Sócios, Econômicos, Culturais e Ambientais Provocados pela Atividade Turística no Município de Tibau do Sul/ RN. Relatório Técnico - SEBRAE-RN.

Guerra, A.J.T.; Silva, A.S.; Botelho, R.G.M. 1999. Erosão e conservação dos solos: conceitos, temas e aplicações. Rio de Janeiro: Ed. Bertrand Brasil S.A., p.17-18.

Guerra, A.J.T. 1994. Processos Erosivos nas Encostas. In: GUERRA, A.J.T.; CUNHA S.B. Geomorfologia: uma atualização de bases e conceitos. Rio de Janeiro: Bertrand Brasil S.A., p.149208.

Silva, W. S. 2003 Estudo da dinâmica superficial e geotécnica das falésias do município de Tibau do 
Braz. J. Aquat. Sci. Technol., 2005, 9(1):31-37.

Sul - Litoral Oriental do RN. Dissertação de Mestrado, Universidade Federal do Rio Grande do Norte. Centro de Tecnologia, Programa de Pós-graduação em Engenharia Sanitária.
Amaral, R.F.A., 2001. Dinâmica Ambiental e o Problema da Erosão na Zona Costeira do Município de Tibau do Sul. IDEMA, Relatório Técnico. 45 p.

Submetido: Outubro/2004

Revisado: Fevereiro/2005

Aceito: Agosto/2005 